\title{
A CASE OF PRIMARY INTRAMEDULLARY TUMOR
}

\author{
Florin Scarlatescu \\ Department of Neurology, Coltea Clinical Hospital, Bucharest
}

\begin{abstract}
Primary spinal cord tumors are rare neoplasms that can lead to significant patient disability and mortality. Given their rarity, they are often misdiagnosed, especially in the early stages, when a high index of suspicion is required. In rare cases of spinal cord tumors there may be a discrepancy between the sensory level and the real site of the tumor. This phenomenon, called "false localizing sign" is rare but well known and, if unrecognized, may delay the appropriate diagnosis and treatment.

The aim of this work is to present a clinical case with a false localizing low thoracic sensory level due to an upper thoracic grade II ependymoma.
\end{abstract}

Keywords: spinal cord ependymoma, false localizing level of sensibility

\section{INTRODUCTION}

Primary spinal cord tumors account for $4-10 \%$ from all central nervous system tumors (1). They are classified as extradural and intradural (extramedullary and intramedullary) with a reported incidence of the intradural tumors of 0.3 per 100,000 per year, most of them extramedullary (2). While meningiomas and nerve sheath tumors represent the most common intradural extramedullary tumors, astrocytomas and ependymomas represent the most common intramedullary tumors (1). The classical presentation of intradural tumors consists of progressive sensorimotor spinal tract syndrome or progressive painful radicular-spinal cord syndrome (3), most of them are resectable (1) and the functional outcome depends mainly on the preoperative neurological status $(3,4)$ and tumor histology (4).

Spinal cord ependymomas (a type of spinal cord gliomas) are rare, generally slow growing tumors arising from the ependymal cells linning the central canal in the spinal cord. The 2007 World Health Organisation grade classification (3) comprises the following types of ependymal cell tumors: myxopapillary ependymoma, grade I (subependymoma), grade II (ependymoma, the most common) (5) and grade III (anaplastic ependymoma, the most malignant type with more rapidly evolution and poor prognosis) $(4,5)$. These tumors appear in the third or fourth decade of life, they are generally located in the cervical and upper thoracic spine and they are associated with syrinx formation in two of three cases (4).

The "false localizing signs" represent an exception from the close clinicoanatomical correlation that represents the base of neurological semiology. They occur either as a consequence of raised intracranial pressure (the most common is the sixth nerve paresis) or with spinal cord lesions (6). The possibility of a truncal sensory loss level as a false localizing sign is rare but well known and must be kept in mind when diagnosing spinal cord syndromes.

\section{CASE REPORT}

A 39 years old previously healthy non-smoker female presented for severe knife-like back pain for approximate eight weeks, intensified by coughing and sneezing. The general physical exam was normal and the neurological exam disclosed only a severe reduction of pain and temperature perception below a T12 level.

The routine paraclinical exams (chest X-ray, usual blood tests including complete blood cell count and coagulogram) were normal.

A magnetic resonance imaging (MRI) at the suspected level was performed and the results were 
normal (Fig. 1,2). A follow-up MRI revealed an upper thoracic intramedullary gadolinium-enhancing tumor (T2-T3, Fig. 3-5). The patient was referred to neurosurgery with successful removal of the tumor (histopathological result: grade II ependymoma) and a good clinical outcome (modified Rankin Scale 1 at three months and one year and no sign of relapse on MRI exam).

\section{CONCLUSIONS}

The particularities of this case consist in the presence of a false localizing sign as the only pathological sign on physical exam and, of course, the rarity of the tumor itself. In this case only a careful and extensive paraclinical exam could help to make an early diagnostic and to establish the appropriate
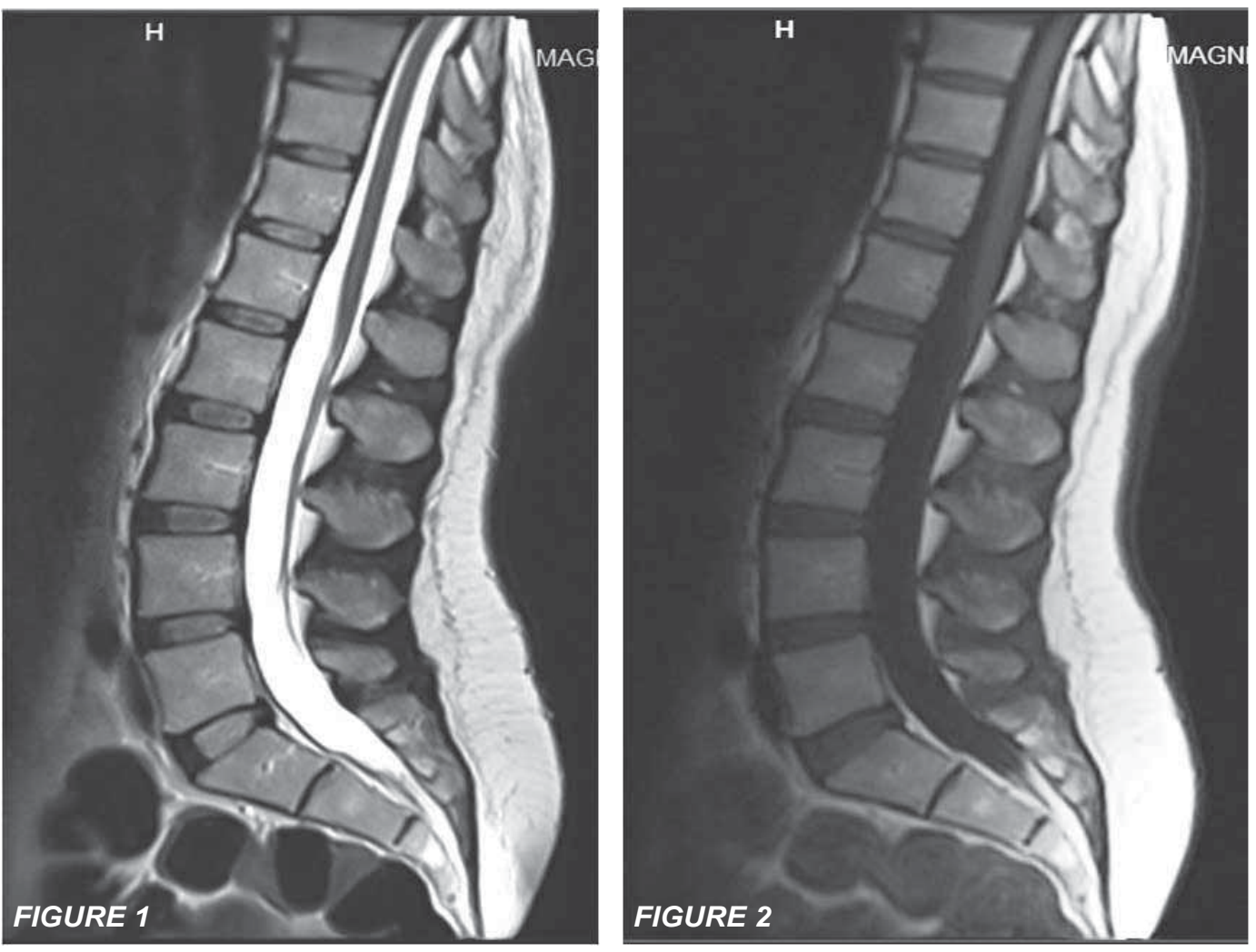

FIGURES 1,2. Native $M R I$ at suspected site of the lesion: normal results: 1) T2 sagital; 2) T1 sagital
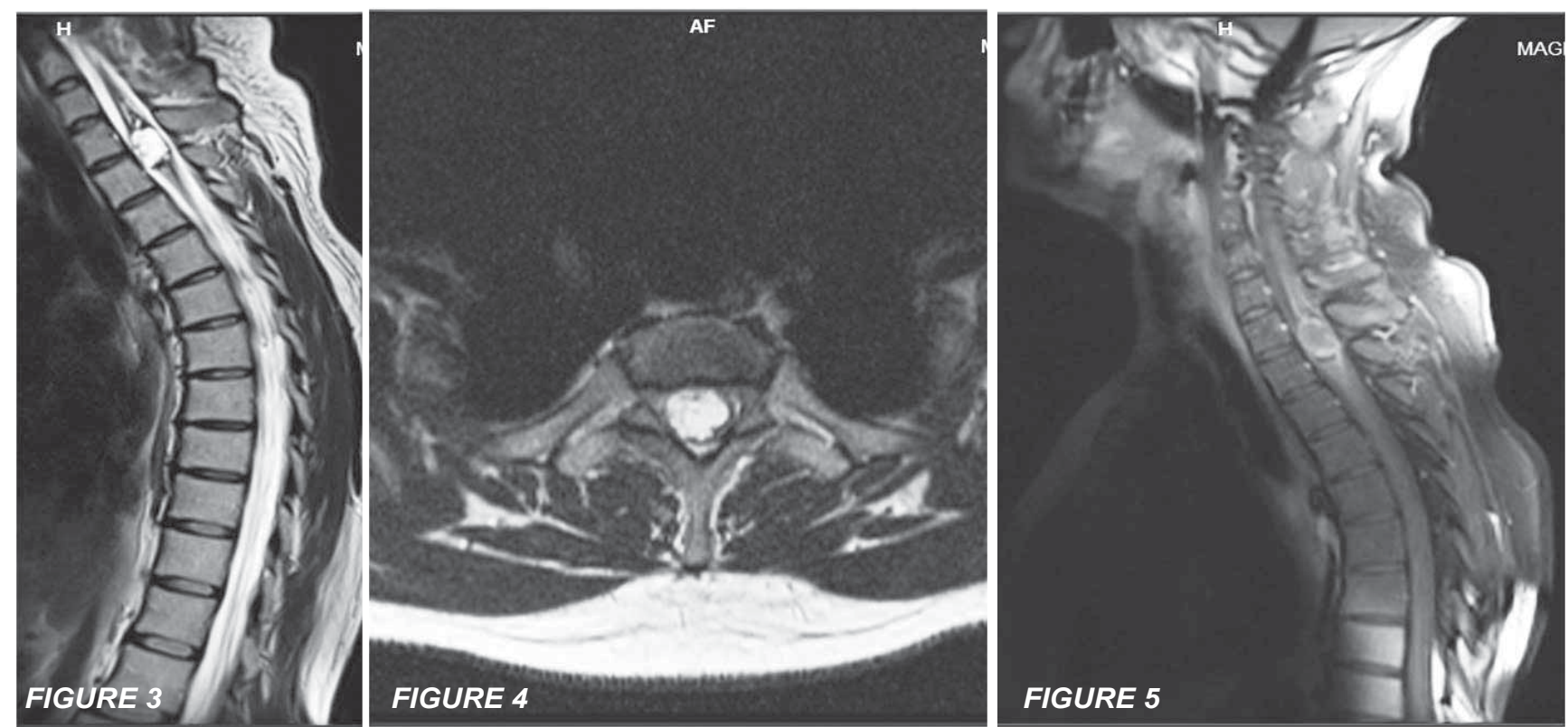

FIGURES 3-5. Follow-up MRI: upper thoracic intramedullary tumor (T2-T3). 3) T2 sagital; 4)T2 axial; 5) T1 sagital with contrast. 
treatment measures. In conclusion, a possible false localizing sign should always be considered when investigating a patient with a thoracic level of sen-

\section{REFERENCES}

1. Segal D., Lidar Z., Corn A. et al. Delay in diagnosis of primary intradural spinal cord tumors, Surg Neurol Int 2012; 3:52.

2. Jenkinson M.D., Simpson C., Nicholas R.C. et al. Outcome predictors and complications in the management of intradural spinal tumors, Eur Spine J 2006;15(2):203-210.

3. Ropper A.H., Samuels M.A., Klein J.P. Adams and Victor's Principles of Neurology, $10^{\text {th }}$ edition, McGraw-Hill Education, 2014.

4. Samartzis D., Gillis C.C., Shih P. et al. Intramedullary spinal cord tumors: part 1- Epidemiology, Pathophysiology and Diagnosis, Global Spine J 2015 Oct; 5(5):425-435. sory loss and normal MRI exam at the suspected site of the lesion.

5. Vera-Bolanos E., Aldape K., Yuan Y. et al. Clinical course and progression-free survival of adult intracranial and spinal ependymoma patients, Neuro Oncol 2015; 17(3):440-447.

6. Larner A.J. False localizing signs, J Neurol Neurosurg Psychiatry $2003 ; 74: 415-418$ 